\title{
Analysis on the Restriction of Service Resources in the Independent Innovation Capacity of Manufacturing Enterprises in Liuzhou
}

\author{
Danyang Wang a, Lu Ma \\ School of Management, Guangxi University of Science and Technology, Liuzhou, Guangxi, China \\ a964216798@qq.com
}

\begin{abstract}
Service resource is one of the factors affecting the performance of enterprise innovation. Through the investigation, and from the regional infrastructure construction in Liuzhou, the number of science and technology institutions, public libraries and education funds four indicators measuring manufacturing enterprise service resources, Guangxi and Nanning, a comparative analysis of Guilin and Wuzhou three city, the constraint factors in Liuzhou manufacturing enterprise service resources eventually found, and put forward countermeasures and measures of how to enhance the innovation capability of manufacturing enterprises in Liuzhou.
\end{abstract}

Keywords: Liuzhou; Manufacturing Enterprises; Service Resource.

\section{Introduction}

Along with the further development of the arrival of the era of knowledge economy and economic globalization, innovation for the rapid growth of enterprises become more and more important [1]. Service resources elements as a kind of enterprise innovation environment, the elements of the supply conditions on the performance of manufacturing enterprises is very important. The study found, innovation resources environment is constraints to technological innovation, technological innovation of enterprises cannot be separated from the external complementary resource support and has severe dependence [2].

\section{Service Resources}

Service resource is an enterprise can obtain the necessary innovation activities of various public and professional mediation services from outside, in order to accelerate the success of their innovation activities [3, 4]. According to sources of service channels, it can be divided into the government's public service resources and social intermediary services resources (Table 1).

Table 1 Summary of Resource Elements

\begin{tabular}{ccc}
\hline Resource factor & Second level index & Measurement content \\
\hline & Regional infrastructure construction & Highway mileage ; \\
Nervice & Number of scientific and technological subscribers \\
resources & institutions & Relevant departments of scientific \\
& public library & research institutions \\
& Education funds & Number of public libraries and the \\
Internet user & The actual cost of education in the budget \\
& Number of Internet users \\
\hline
\end{tabular}

Rong Fei and other scholars believe that regional infrastructure construction, the efficiency of the government, science and technology institutions, intermediary services, public library, education funds and index can used to evaluation of service resources. In this study, the combination of indicators available and the impact on enterprise innovation factors into consideration, with the regional infrastructure, the number of scientific and technological institutions, public libraries, educational funds and Internet users to measure service resource elements [5,6]. 


\subsection{Regional Infrastructure Construction.}

Regional infrastructure consists of two indicators of highway mileage $(\mathrm{km})$ and telephone subscribers (10000 households). In view of these two indicators, the specific conditions of Liuzhou and the comparison with other major cities in Guangxi as shown in Table 2 and Table 3.

Table 2 Guangxi Main City Road Mileage Construction in 2010-2014 (Kilometer)

\begin{tabular}{cccccc}
\hline & 2010 & 2011 & 2012 & 2013 & 2014 \\
\hline Nanning & 10567 & 11527 & 11817 & 12195 & 12458 \\
Liuzhou & 7957 & 8013 & 8017.9 & 8085 & 8156 \\
Guilin & 11186 & 11287 & 11423 & 11784 & 13859 \\
Wuzhou & 4054 & 6009 & 956 & 5841 & 5619 \\
\hline
\end{tabular}

Table 3 Guangxi Major Urban Telephone Subscribers in 2010-2014 (10000 Households)

\begin{tabular}{cccccc}
\hline & 2010 & 2011 & 2012 & 2013 & 2014 \\
\hline Nanning & 604.4 & 791.8 & 824.72 & 852.62 & 830.54 \\
Liuzhou & 285.4 & 311.3 & 242.08 & 375.32 & 405.12 \\
Guilin & 427.1 & 455.1 & 400.19 & 434.04 & 456.4 \\
Wuzhou & 157.8 & 163.67 & 192.08 & 202.33 & 195.77 \\
\hline
\end{tabular}

As shown in Table 2, 2010 to 2014 years in major cities in Guangxi highway mileage showed a growth trend, and highway mileage in the 2014 Guilin occupies first place, Nanning second, third Liuzhou, Wuzhou in.2014 in the fourth compared with 2010, Guilin maximum growth rate, was 23.9\%; Nanning growth rate was 15.2\%; Liuzhou growth rate was $2.5 \%$; Wuzhou growth rate was $38.6 \%$. That Liuzhou in recent years, the highway infrastructure construction to increase strength is not great, has the potential to become a business development and market development constraints.

As shown in table 3, telephone subscribers had an increasing trend from 2010 to 2014 years in major cities in Guangxi , and in 2014 the number of telephone users in Nanning occupies first place, Guilin second, third Liuzhou, Wuzhou in. And 2014 in the fourth compared with 2010, Nanning maximum growth rate $37.4 \%$; Guilin growth rate was $6.9 \%$; Liuzhou growth rate was $42.0 \%$; Wuzhou growth rate was $24.1 \%$. That Liuzhou in recent years of urban telephone subscribers number has a higher growth rate, is conducive to business and market development.

\subsection{Collection of Public Libraries.}

The public library is the important elements in the system of public cultural services and the broad masses of the people of the dissemination of knowledge and information, is advantageous to the social education and public intellectual development and the cultural heritage plays a protective effect. As shown in Table 4, the number of major cities in Guangxi Library and the collection of data.

Table 4 The Number and the Volume of Books in the Main Cities of Guangxi in 2014

\begin{tabular}{cccc}
\hline & Number of Libraries & Collection of books (thousands) & $\begin{array}{c}\text { Per capita volume of books (1000 } \\
\text { copies) }\end{array}$ \\
\hline Nanning & 17 & 8955.7 & 1.30 \\
Liuzhou & 11 & 1826.8 & 0.47 \\
Guilin & 13 & 1520 & 0.31 \\
Wuzhou & 5 & 1051.9 & 0.35 \\
\hline
\end{tabular}

From Table 4 can know, in 2014, Nanning public library number to 17, Liuzhou to 11, Guilin to 13, Wuzhou to 5; major cities in Guangxi Library per capita amount, Nanning ranked first, Liuzhou second, Wuzhou ranked third, Guilin ranked fourth. Although the second row of the willow, the per capita amount of books, but the gap with the Nanning is relatively large, so it can be considered appropriate to increase the amount of books, in order to give full play to the educational function of the public library.

\subsection{Number of Scientific and Technological Institutions.}

The number of scientific and technological institutions refers to the scientific research institutions in the science and Technology Department, large and medium-sized industrial enterprises and 
full-time institutions of higher learning. Here, the data in 2010-2014, the specific situation as shown in Table 5. And Nanning, Liuzhou and Guilin Institute of technology, to the largest number of year is 2011, Wuzhou institutions of science and technology to the largest number of years is 2014. In addition to Wuzhou, Nanning, Liuzhou and Guilin Institute of technology, the number were higher than average level in Guangxi. That is at the forefront of Nanning, Liuzhou and Guilin technology compared to other prefecture level city in Guangxi, but still should increase science and technology institution building efforts, speeding up the transformation of scientific and technological achievements of the city, promote scientific and technological innovation, to promote the development of economy and technology.

Table 5 Quantity of Science and Technology Institutions in Major Cities of Guangxi (A)

\begin{tabular}{cccccc}
\hline & 2010 & 2011 & 2012 & 2013 & 2014 \\
\hline Guangxi average & 25.07 & 34.07 & 30.21 & 31.93 & 30.07 \\
Nanning & 109 & 157 & 134 & 119 & 100 \\
Liuzhou & 79 & 199 & 110 & 108 & 113 \\
Guilin & 55 & 80 & 52 & 66 & 72 \\
Wuzhou & 15 & 20 & 18 & 28 & 30 \\
\hline
\end{tabular}

\subsection{Education Funds.}

National financial education funding for school improvement, the development of the students have a great significance. Table 6 shows the 2010-2014 years, the main city of Guangxi investment in education. Between 2010 and 2014, Guangxi region, the average expenditure on education and major cities in Guangxi education funds showed increasing trend, but Liuzhou and Wuzhou education funding less than average level of funding for education in Guangxi. After analysis. The average of Guangxi, Nanning, Liuzhou, Guilin, Wuzhou, the growth rate of $80.1 \%, 75.6 \%, 62.8 \%, 59.3 \%$, $80.1 \%$. The above data can be found, comparable Wuzhou growth rate and Guangxi's average level, and the growth rate of the other three cities, are less than average level in Guangxi.Through the above data analysis, Liuzhou should increase investment in education, training and improve people's ability to work, and thus promote the development of science and technology in Liuzhou.

Table 6 Major Urban Education Funding In Guangxi (100 Millon Yuan)

\begin{tabular}{cccccc}
\hline & 2010 & 2011 & 2012 & 2013 & 2014 \\
\hline Guangxi average & 26.24 & 32.73 & 42.01 & 43.55 & 47.23 \\
Nanning & 42.98 & 53.55 & 66.07 & 70.32 & 75.48 \\
Liuzhou & 27.91 & 34.45 & 40.32 & 42.04 & 45.44 \\
Guilin & 33.53 & 39.84 & 31.5 & 49.73 & 53.43 \\
Wuzhou & 21.13 & 27.31 & 37.78 & 37.61 & 38.03 \\
\hline
\end{tabular}

\subsection{Internet User.}

Internet users in Guangxi city the main computer data collation as shown in Table 7. By comparison, the growth rate of Liuzhou is higher than that of other major computer Internet users in Guangxi industrial city, Nanning, Guilin and Wuzhou. At present, the global Internet has become one of the world's important information infrastructure for economic development and social progress. The high growth rate of Liuzhou computer Internet users to promote the Liuzhou information process, rich enterprise operation mode, enhance its core competitiveness.

Table 7 Computer Internet Users in Guangxi Main City (Million)

\begin{tabular}{cccccc}
\hline & 2010 & 2011 & 2012 & 2013 & 2014 \\
\hline Nanning & 90.8 & 426.7 & 504.85 & 161.8 & 166.78 \\
Liuzhou & 61.7 & 56.4 & 58.85 & 64.8 & 123.15 \\
Guilin & 39.7 & 50.8 & 60.6 & 67.14 & 72.7 \\
Wuzhou & 17.26 & 22.4 & 109.52 & 25.35 & 28.33 \\
\hline
\end{tabular}




\section{Conclusion}

Through the regional infrastructure construction of Liuzhou science and Technology Agency, the number of public libraries, analysis service resources educational funds, and with the Guangxi Nanning, Guilin, Wuzhou and other major city comparison, found the following problems: Liuzhou in recent years, the highway infrastructure construction with high intensity, is likely to become the enterprise business development restricting factors of market development; the higher rate of growth in the number of city telephone users, is conducive to business development, market development constraints; need to appropriately increase the amount of books, in order to give full play to the public library's education function; should increase the science and technology institution building efforts, accelerate the transformation of the city of scientific and technological achievements, and promote scientific and technological innovation, promote technology and economy the development of; increasing education investment, foster and enhance the ability to work, and promote the development of science and technology in Liuzhou. Therefore, the government of Liuzhou in the future service resources construction, should increase the fund's investment and management, and provide a good environment for the independent innovation of the manufacturing industry.

\section{Acknowledgments}

This research was financially supported by the Liuzhou Science and Technology Department's Soft Science Program of 2013, NO2013J040404.

\section{References}

[1] Koskela-Huotari K, Bo E, Jonas J M, et al. Innovation in service ecosystems-breaking, making, and maintaining institutionalized rules of resource integration [J]. Journal of Business Research, 2016, 69(8):2964 - 2971.

[2] Zhang J, Wei Q, Zhang Q, et al. Pricing, service and preservation technology investments policy for deteriorating items under common resource constraints [J]. Computers \& Industrial Engineering, 2016, 95(C):1-9.

[3] Tao F, Hu Y F, Zhou Z D. Study on manufacturing grid \& its resource service optimal-selection system [J]. International Journal of Advanced Manufacturing Technology, 2008, 37 (9-10): 1022-1041.

[4] Tao F, Hu Y, Zhao D, et al. Study on resource service match and search in manufacturing grid system [J]. International Journal of Advanced Manufacturing Technology, 2008, 43(3):379-399.

[5] Hu Y, Tao F, Zhao D, et al. Manufacturing grid resource and resource service digital description [J]. International Journal of Advanced Manufacturing Technology, 2009, 44 (9-10): 1024-1035.

[6] Wen B, Luo Z, Liang P. toward Customer-Centric SOA: Services Resource Active Provisioning Approach [J]. Journal of Software, 2014, 9(4):1007-1018.

[7] Somsuk N, Wonglimpiyarat J, Laosirihongthong T. Technology business incubators and industrial development: resource-based view [J]. Industrial Management \& Data Systems, 2013, volume 112 (112): 245-267.

[8] Sá C, Lee H. Science, business, and innovation: understanding networks in technology-based incubators [J]. R \& D Management, 2012, 42 (3): 243 - 253.

[9] Bian C, Jiang W, Greatbatch R J. An exploratory model study of sediment transport sources and deposits in the Bohai Sea, Yellow Sea, and East China Sea [J]. Journal of Geophysical Research Oceans, 2013, 118 (11): 5908-5923. 